\title{
Statins for Secondary Stroke Prevention in Patients without Known Coronary Heart Disease: The Jury Is Still Out
}

\author{
Larry B. Goldstein $^{a}$ Pierre Amarenco ${ }^{b}$ Julien Bogousslavskyc \\ Alfred S. Callahan ${ }^{d}$ Michael G. Hennericie K. Michael A. Welch ${ }^{f}$ \\ Justin Ziving Henrik Sillesen ${ }^{\mathrm{h}}$ \\ aDuke University Medical Center, Durham, N.C., USA; bHôpital Lariboisière, Paris, France; \\ ${ }^{c}$ Centre Hospitalier Universitaire, Lausanne, Switzerland; d Neurologic Consultants P.C., Nashville, Tenn., USA; \\ ${ }^{\mathrm{e}}$ Klinikum Mannheim, Mannheim, Germany; ${ }^{\mathrm{f} F i n c h}$ Chicago Medical School, Chicago, III., and \\ gUniversity of California San Diego, San Diego, Calif., USA; h Gentofte Hospital, Hellerup, Denmark
}

Several previous studies have shown that statin therapy can reduce the risk of stroke in patients with coronary heart disease (CHD) [1-3]. Aside from the Medical Research Council Heart Protection Study (HPS) [4], there remains little data on the impact of statin therapy in patients with symptomatic cerebrovascular disease but no known CHD.

Consistent with other studies, the HPS found that statin therapy was associated with a $25 \%$ reduction in the risk of stroke (risk ratio $0.75,95 \%$ CI: $0.66-0.85, \mathrm{p}<$ 0.0001) [4]. The stroke rate in the HPS was much lower than that of a typical stroke population ( $1 \%$ per year in the HPS as compared to $3-5 \%$ per year). Of the end point strokes, $30 \%$ were not classified as being due to ischemia or bleeding. Of the 20,536 patients enrolled in the HPS, 1,820 patients had cerebrovascular disease but no history of CHD. There was a $21 \%$ relative risk reduction $(95 \%$ CI: 0.055-0.339) in major vascular events in this subgroup. The HPS patients were not prospectively randomized within disease strata, however, and there may have been imbalances in stroke risk factors between the groups. Patients with transient ischemic attacks (TIAs) were included in the study, but it is unclear how this diagnosis was established. Finally, although the risk of major vascular events was reduced, the impact of statin therapy on recurrent stroke in the 1,820-patient stroke subgroup was not reported. Therefore, although the data from the HPS are consistent with, the results are not definitive of, a benefit from statin use in stroke patients.

In PROSPER, a study focused on a population of persons over the age of 70 at risk of developing CHD and stroke [5], the composite end point of CHD death, myocardial infarction and stroke was significantly reduced by $23 \%$ with statin treatment. Of those with stroke at baseline, approximately $11 \%$ were not analyzed separately and the overall risk of stroke was unaffected by statin treatment (hazard ratio 1.03, 95\% CI: 0.81-1.31, p = $0.8)$.

Most recently, the lipid-lowering arm of the ASCOT study was stopped because of a significant benefit in the statin-treated group [6]. ASCOT assessed the effects of a statin in primary prevention of CHD in hypertensive patients with average or lower-than-average cholesterol levels but at least 3 other cardiovascular risk factors. There was an overall $36 \%$ risk reduction (hazard ratio $0.64,95 \%$ CI: $0.50-0.83, p=0.0005)$ with statin treat-

\begin{tabular}{ll}
\hline KARGER & ( ) 2004 S. Karger AG, Basel \\
Fax +4161306 1234 & 1015-9770/04/0181-0001\$21.00/0 \\
$\begin{array}{l}\text { E-Mail karger@karger.ch } \\
\text { www.karger.com }\end{array}$ & $\begin{array}{l}\text { Accessible online at: } \\
\text { www.karger.com/ced }\end{array}$
\end{tabular}

Henrik Sillesen

Department of Vascular Surgery

Gentofte University Hospital

DK-2900 Hellerup (Denmark)

Tel. +45 3977 3202, Fax +45 3977 7674, E-Mail hens@gentoftehosp.kbhamt.dk 
ment and a significant $27 \%$ risk reduction (hazard ratio $0.73,95 \% \mathrm{CI}: 0.56-0.96, \mathrm{p}=0.024)$ for fatal and nonfatal stroke. Approximately $10 \%(n=1,001)$ of the patients had prior stroke or TIA. As for PROSPER, data of patients with prior cerebrovascular disease were not analyzed separately. No additional data exist to support the contention that patients with stroke or TIA without known CHD derive a benefit from statin therapy. Although statins have been recommended by the NCEP-III panel for patients with cerebrovascular disease, this treatment was limited to those with carotid disease (as a CHD equivalent) and received a level $\mathrm{C}$ recommendation (i.e., expert opinion) [7].

Patients presenting with cerebrovascular disease have higher rates of stroke, and therefore constitute a different population, than those formally studied in other statin trials, although these patients may have comprised a segment of the studied populations. Whether patients presenting with cerebrovascular disease should be treated with a statin remains a critical but unanswered clinical question. Accordingly, a dedicated secondary prevention trial in patients with previous TIA or stroke without CHD is of paramount importance. The SPARCL trial (Stroke Prevention by Aggressive Reduction in Cholesterol Levels) has randomized 4,700 patients with previous TIA or stroke to either $80 \mathrm{mg}$ atorvastatin or placebo and is expected to reach the projected 540 primary end points during the fall of 2004 [8]. From the end point profile observed thus far, SPARCL patients represent a unique cohort different from those included in previous studies; the annual stroke rate in SPARCL is 3.5\%/year ( $>3$ times that in other statin trials) and the cardiac event rate is $<1 \%$ /year (approximately $1 / 3$ that reported in other statin trials). The SPARCL trial is only 1 year from completion. The data safety management board has recently reviewed the last of 5 interim analyses (September 2003), and recommended to continue the clinical trial as planned. The SPARCL trial will answer an essential clinical question, i.e. whether patients with stroke or TIA without CHD should be treated with a statin.

\section{References}

1 Scandinavian Simvastatin Survival Study Group: Randomised trial of cholesterol lowering in 4,444 patients with coronary heart disease: The Scandinavian Simvastatin Survival Study (4S). Lancet 1994;344:1383-1389.

2 LIPID Study Group: Prevention of cardiovascular events and death with pravastatin in patients with coronary heart disease and a broad range of initial cholesterol levels. The longterm Intervention with Pavastatin in Ischaemic Disease (LIPID) study group. N Engl J Med 1998;339:1349-1357.

3 Plehn JF, Davis BR, Sacks FM, Rouleau JL, Pfeffer MA, Bernstein V, Cuddy TE, Moye LA, Piller LB, Rutherford J, Simpson LM, Braunwald E: Reduction of stroke incidence after myocardial infarction with pravastatin. The Cholesterol and Recurrent Events (CARE) Study. Circulation 1999;99:216-223.
4 Heart Protection Collaborative Study Group: $\mathrm{MRC} / \mathrm{BHF}$ heart protection study of cholesterol lowering with simvastatin in 20,536 highrisk individuals: A randomised placebo-controlled trial. Lancet 2002;360:7-22.

5 Shepherd J, Blauw GJ, Murphy MB, Bollen EL, Buckley BM, Cobbe SM, Ford I, Gaw A, Hyland M, Jukema JW, Kamper AM, Macfarlane PW, Meinders AE, Norrie J, Packard CJ, Perry IJ, Stott DJ, Sweeney BJ, Twomey C, Westendorp RG: Pravastatin in elderly individuals at risk of vascular disease (PROSPER): A randomised controlled trial. Lancet 2002; 360:1623-1630.

6 Sever PS, Dahlof B, Poulter NR, Wedel H, Beevers G, Caulfield M, Collins R, Kjeldsen SE, Kristinsson A, McInnes GT, Mehlsen J, Nieminen M, O’Brien E, Ostergren J: Prevention of coronary and stroke events with atorvastatin in hypertensive patients who have average or lower-than-average cholesterol concentrations, in the Anglo-Scandinavian Cardiac Outcomes Trial - Lipid Lowering Arm (ASCOT-LLA): A multicentre randomised controlled trial. Lancet 2003;361:1149-1158.
7 Expert Panel on Detection Evaluation and Treatment of High Blood Cholesterol in Adults: Executive summary of The Third Report of The National Cholesterol Education Program (NCEP) Expert Panel on Detection, Evaluation, And Treatment of High Blood Cholesterol In Adults (Adult Treatment Panel III). JAMA 2001;285:2486-2497.

8 The SPARCL Investigators: Design and baseline characteristics of the Stroke Prevention by Aggressive Reduction in Cholesterol Levels (SPARCL) Study. Cerebrovasc Dis 2003;16: 389-395. 